III.

\title{
Full-term Ectopic Pregnancy; Abdominal Section Five Weeks after the Death of the Child; Death from Hæmorrhage and Septic Absorption.
}

\author{
By John S. Fambaikn, M.A., M.B. (Oxon.), \\ Assistant Obstetric Physician, St. Thomas's Hospital, London.
}

S.H., xet. 34, was admitted on August 20th, 1905, to St. Thomas's Hospital from the British Lying-in Hospital, where she had first come under my charge. Her history was as follows:- She had had five pregnancies, the last three years ago, and her last menstrual period had occurred in September, 1904, i.e. eleven months before admission. In January, 1905, when she was supposed to be three to four months pregnant, she had had a severe attack of abdominal pain, chiefly on the right side, with constipation and vomiting, from which she had recovered after the use of copious enemata. She had been greatly troubled with constipation throughout the remainder of her pregnancy, and generally had had to get up two or three times in the night to pass water, but had been free from pain. On July the 12th, the pains recurred and she thought she was about to be confined. On July the 14th, she was first seen by her doctor, who found the abdomen very sensitive, and distinct evidences of the child being alive; on vaginal examination there was no sign of commencing labour. On July 15th, there were violent movements of the child, and on the 16 th they ceased altogether and were not felt again. On the 17 th , the doctor again saw her. He fonnd the abdomen very tender, but no distension was present apart from the pregnancy.

The patient, after this, had less pain, but suffered greatly from sickness and loss of appetite, and in consequence lost flesh and began to feel weak. On August the 15th, she was sent up to the British Lying-in Hospital as a case of retention of a dead child in utero. I saw her first on the 18th, and found considerable difficulty in deciding whether the fotus was inside or outside the uterus. The child could be plainly felt on abdominal examination, except that the vertex could not be gripped between the fingers at the pelvic brim. On vaginal examination, the cervix was found to be soft and somewhat patulous, but no part of the child could be felt in the pelvis. 
On forcing the finger through the cervical canal it appeared to impinge upon a firm substance, which suggested placental tissue and organized blood-clot. Some portion of this tissue came away on the finger and was reserved for examination; it looked like placental tissue. On the following day the diagnosis was made certain by an examination under anæsthesia. The cervical canal was dilated and the uterus explored with the finger; its cavity was found to be empty and lined by a thick decidual membrane; the lower pole of the swelling lay behind the uterus. The result of even so trifling a procedure as this was to increase the pulse rate and to add considerably to the general weakness of the patient.

On admission to St. Thomas's Hospital, she was noticed to be much emaciated, with sunken eyes. The pulse rate was 110; the temperature was $99 \cdot 4^{\circ}$. The breasts were flaccid. There was a large rounded swelling in the abdomen extending to within an inch and a half of the xiphoid cartilage; the umbilicus was deeply pigmented and was flush with the surface. On palpation the tumour was elastic, and gave a well-marked fluid thrill. The breech and feet could be made out in the left upper quadrant and the back traced downwards towards the middle line, but no definite part could be made out in the lower pole. No fœetal heart sounds could be heard and no fœtal movements felt. The abdominal tumour was somewhat tender to palpation.

The abdomen was opened on August 25th. A dark cystic tumour presented itself, which appeared to be entirely retro-peritoneal. The uterus was below and in front, and the pouch of Douglas was raised up so as to form a shallow depression between the sac and the posterior wall of the uterus. As far as could be seen the bowels were lifted up in the abdomen and lay behind the sac; on the right side the peritoneum had been so far stripped up that the cæcum was slightly spread out on its wall. The sac was packed round with sponges and opened. It contained a dark-coloured fluid, with a sickly, but quite inoffensive, odour; cultures and smears were taken from it for bacteriological examination. The foetus was removed and an attempt made to remove the placenta which was attached to the lower and posterior wall of the sac at about the level of the pelvic brim. The detachment of even a small edge caused such furious bleeding that the condition of the patient at once became serious. The cavity was plugged with a number of abdominal sponges, the redundant sac wall cut away, and the rest sutured to the abdominal incision. By the time the patient was back in bed she was almost pulseless; an intra-venous infusion of saline solution 
was therefore at once given. The macerated fœtus weighed $8 \mathrm{lbs} .2 \mathrm{oz}$. , and was $21 \frac{3}{4}$ in. in length.

In spite of the plugging the patient bled through her dressings, which had to be changed three times, and on two of these occasions the amount was so great that not only were the dressings and bandages soaked but the bed sheet also. After the third dressing there was no further bleeding, and in the morning there was very little blood on the bandages. During the night she had frequent hypodermic injections of strychnine and injections of saline solution into the bowel, and by the morning of the 26th she had rallied considerably. The sponges were gradually removed, and when the last were taken out on the 28th they were already offensive. The cavity was then washed out with hydrogen peroxide solution and dressed three times daily. There was a slight blood-stained watery discharge of a putrid odour, and signs of general septic intoxication soon became manifest. The temperature reached $100^{\circ}$ on the 28 th, $1023^{\circ}$ on the 30 th, and $103^{\circ}$ on the 31 st, and the pulse rate, which had dropped back to what it had been before the operation, rose to 116 to 120. As the patient was evidently going downhill from septic absorption it was decided to make another effort to remove the placenta. Un September 1st, the cavity was explored and a portion of very foul, stinking placenta removed, but the hæmorrhage became so great that it was necessary to plug the cavity again and to abandon further efforts. The woman died a few hours later.

Abstract of post mortem report. There were no evidences of peritonitis. The sac lay in front of the main peritoneal cavity, and although it could be easily drawn out of the abdomen, its base of attachment was very extensive, the peritoneal reflection being from right broad ligament to meso-cæcum. The pregnancy had developed in the broad ligament of the right side. The sac contained a large breaking-down placenta, measuring $8 \times 5 \frac{1}{2} \times 3$ in., and showed at one part the results of the attempt to remove it. It was attached to the tissues of the base of the broad ligament. The uterus was equal in size to a tennis ball, and contained a little decidua; the left uterine appendages were normal. The blood was remarkably fluid.

The cultures taken from the sac at the time of operation were examined in the clinical laboratory and reported on by Dr. Dudgeon as follows:-(a) Film of fluid shows large numbers of phagocytes and groups of small cocci and diplococci, some intra-cellular and some extra-cellular. (b) Both aërobic and anaërobic cultures from fluid are sterile. 
There are several points in this case which are worthy of comment.

The diagnosis was not definitely made till the finger had been passed into the uterus. From the history the exact nature of the attack of pain was uncertain and the period of pregnancy at which it occurred (3rd to 4th month) seemed rather late for a primary rupture, though the prolonged period of amenorrhcea was against a uterine pregnancy. The tumour was quite central, and there was nothing in the appearance of the abdomen to suggest that the fotus was not in the uterus. Nor was there anything unusual on palpation except that there seemed to be something at the pelvic brim which prevented the head being grasped between the hands as in an ordinary vertex presentation. When, however, no part of the

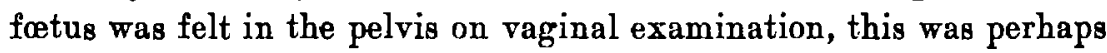
the most suggestive sign. The difficulty was increased by the fact that at times it was thought that rhythmical uterine contractions were felt over the tumour. The firm mass which could be felt at the top of the cervical canal turned out to be the decidua covering the uterine wall, but it conveyed the sensation which would be produced by a mass of fibrous placental tissue within the uterus. This impression was strengthened by the appearance of the shreds of tissue which came away, but the absence of any history of vaginal hæmorrhage during the pregnancy was against its being correct. An examination under anæsthesia made matters quite certain before the operation was undertaken. Had the patient's condition permitted it, I should have preferred to wait a little longer before operating; but, though there was no evidence of infection of the sac, the steady deterioration in her general condition prevented further delay.

The pregnancy was evidently tubo-ligamentary, as the posterior layer of the broad ligament and the posterior parietal peritoneum had been raised on the right side as high as the pelvic brim so as to involve the meso-cæcum. The placenta was attached to the base of the sac and was of large size. The sac was formed by the peritoneum raised from the pelvic floor except where the placenta was attached. Here it appeared to be deficient.

The violent hæmorrhage which occurred after separating quite a small area of the placental attachment made further attempts at removal impossible. That the circulation should be so active five or six weeks after the death of the fœtus surprised me. The absence of any putrefactive change may have had something to do with this, as no doubt such change would hasten thrombosis in the placenta] 


\section{Fairbairn: Full-term Tubo-ligamentary Pregnancy 603}

vessels. It did not appear to me to be possible to remove the whole sac owing to the broad base of attachment, but I certainly did not appreciate the extent to which it could be dragged forward, as seen at the post mortem. The week which elapsed between the operation and the death of the patient may, however, have allowed of some shrinking in the attachment of the sac. It certainly appeared at the autopsy as if, by dragging the sac strongly forward, it might have been possible to work in between the base of the sac and the pelvic floor and, by taking away the uterus also, to remove the sac and placenta together. The patient's feeble condition would also have been a deterrent from so extensive an operation, but her recovery from the very large losses of blood which occurred during the operation and after it, showed that she had greater recuperative power than I gave her credit for.

It may be worth while to draw attention to the result of the bacteriological examination of the fluid in the sac. Though the patient had evidently been absorbing deleterious products from the sac, as evidenced by the effect on her general health, the cultures incubated both aërobically and anaërobically, proved sterile. This was also noted in the case of abdominal pregnancy recorded by Maclean in the Jounnal for June last (p. 434), although, there, the sac and its contents had become putrid. 